\title{
Investigation of electrochemical behavior of anisomycin on gold electrode followed by HPLC-MS/MS analysis
}

\author{
Ljiljana Tolić ${ }^{a}$, Jelena Lović ${ }^{b}$, Slobodan Petrovićc ${ }^{c}$, Dušan Mijin ${ }^{c}$, Svetlana Grujić c , \\ Mila Laušević c, Milka Avramov Ivić ${ }^{\text {b,* }}$ \\ a Innovation Center of the Faculty of Technology and Metallurgy, University of Belgrade, Karnegijeva 4, 11000 Belgrade, Serbia \\ b ICTM - Institute of Electrochemistry, University of Belgrade, Njegoševa 12, 11000 Belgrade, Serbia \\ c Faculty of Technology and Metallurgy, University of Belgrade, Karnegijeva 4, 11000 Belgrade, Serbia
}

\section{A R T I C L E I N F O}

\section{Article history:}

Received 6 May 2015

Received in revised form 20 May 2015

Accepted 27 May 2015

Available online 3 June 2015

\section{Keywords:}

Anisomycin

Electroactivity

SWV

HPLC-MS/MS

\begin{abstract}
A B S T R A C T
Anisomycin is an immunosuppressant in low doses $(<0.1 \mu \mathrm{M})$ with possible application in treatment of some autoimmune diseases and in inhibiting transplantation rejection. Anisomycin suppresses malignant tumor cell growth and affects memory. For the first time it was the subject of the electrochemical investigations by cyclic voltammetry and square wave voltammetry on gold electrode in $0.05 \mathrm{M} \mathrm{NaHCO}_{3}$ using its electrochemical activity. The cyclic voltammetry experiments at different sweep rates show that electrochemical process is irreversible and diffusion controlled. Based on square wave voltammetry measurements, the calculated values of LOD and LOQ were 1 and $4 \mathrm{nM}$ (in the absence of biological fluid), as well as 2 and $6 \mathrm{nM}$ (in the presence of spiked urine) indicating the high sensitivity of the proposed electroanalytical method. High performance liquid chromatography-tandem mass spectrometry was a reference method for quantification of anisomycin and served for structural identification of its hydrolysis product (deacetylanisomycin).
\end{abstract}

(c) 2015 Elsevier B.V. All rights reserved.

\section{Introduction}

Anisomycin is a multifunctional antibiotic isolated from two different species of Streptomyces [1]. It is also an inhibitor of protein synthesis [2-5] and affects memory by inhibiting the consolidation of new memories and causing amnesia [6-14]. Anisomycin is an immunosuppressant in low doses $\left(<0.1 \mu \mathrm{M} ; \mathrm{M}=\mathrm{moll}^{-1}\right)$ indicating its possible application in treatment of some autoimmune diseases and in inhibition of the transplantation rejection [4,5]. It suppresses malignant tumor cell growth and can be used as an antitumor agent [15-17]. Anisomycin possesses herbicidal activity and selective activity against pathogenic protozoa and fungi $[18,19]$.

This drug has been identified and analyzed using liquid chromatography, ultraviolet and infrared spectroscopy, as well as mass spectrometry [20-22]. To the best of our knowledge, there are no methods reported for the electrochemical determination of anisomycin.

The aim of this work was to investigate the electrochemical activity of anisomycin on gold electrode using cyclic voltammetry (CV) in $0.05 \mathrm{M}$ $\mathrm{NaHCO}_{3}$. Square wave voltammetry (SWV) was applied for quantitative determination of the drug and in spiked urine samples, followed by high performance liquid chromatography-tandem mass spectrometry (HPLC-MS/MS). The structural identification of anisomycin and its hydrolysis product in $0.05 \mathrm{M} \mathrm{NaHCO}_{3}$ and under the potential cycling

\footnotetext{
* Corresponding author. Tel.: + 381113370389

E-mail address: milka@tmf.bg.ac.rs (M.A. Ivić).
}

conditions in the absence and in the presence of biological sample (urine) was also performed by HPLC-MS/MS.

\section{Experimental part}

\subsection{Chemicals and reagents}

Anisomycin standard (purity $\geq 98 \%$ ) was obtained from Fermentek (Jerusalem, Israel). Used solvents were HPLC grade from SigmaAldrich. Analytical grade trichloroacetic acid (TCA) and $\mathrm{NaHCO}_{3}$ were supplied by Sigma-Aldrich and Merck, respectively. Deionized water was obtained by passing the distilled tap water through a GenPure ultrapure water system (TKA, Niederelbert, Germany).

\subsection{Apparatus and preparation of electrode surfaces}

Standard equipment, PGZ 402 Volta Lab (Radiometer Analytical, Lyon, France) has been used for the electrochemical measurements and the three electrode electrochemical cell was described in detail previously [23]. Polycrystalline gold $\left(0.07 \mathrm{~cm}^{2}\right)$ served as the working electrode and a gold wire as the counter electrode. All the potentials are given vs. saturated calomel electrode (SCE) used as the reference one. Preparation and activation of gold electrode was described previously [23]. Electrolyte, $0.05 \mathrm{M} \mathrm{NaHCO}_{3}(\mathrm{pH}=8.4$ ) was previously deoxygenated by purging with nitrogen at room temperature. SWV operating parameters were: step size $5 \mathrm{mV}$, pulse size $100 \mathrm{mV}$, frequency $2 \mathrm{~Hz}$, and 
scan rate $10 \mathrm{mV} \mathrm{s}^{-1}$, accumulation time $200 \mathrm{~ms}$ at $0.0 \mathrm{~V}$. Standard stock solution of anisomycin at the concentration of $0.37 \mathrm{mM}$ was prepared in methanol and stored at $4{ }^{\circ} \mathrm{C}$. Aliquots of the stock solution were added to electrolyte to obtain concentrations in the range $0.037-14.76 \mathrm{nM}$. The total concentration of methanol did not exceed $4 \%$. The concentration range of anisomycin used in the electrochemical experiment was selected according to reported concentrations of antibiotics in biological fluids [24].

\subsection{Preparation of samples for HPLC-MS/MS analysis}

The sample $(5 \mathrm{ml})$ obtained in the electrochemical experiment was transferred onto clean-up cartridge (Oasis HLB, Waters, Milford, USA) preconditioned with methanol and deionized water. After drying by vacuum suction for $10 \mathrm{~min}$, the analyte was eluted with $5 \mathrm{ml}$ of methanol, evaporated, and reconstituted to the volume of $1 \mathrm{ml}$ with methanol. The sample was filtered through $0.45 \mu \mathrm{m}$ polyvinylidene difluoride filter (Roth, Karlsruhe, Germany) and analyzed by HPLCMS/MS.

The urine was collected from ten healthy volunteers. The sample $(1 \mathrm{ml})$ obtained in the electrochemical experiment with spiked urine was prepared as follows: $10 \mathrm{ml}$ of $5 \%$ solution of TCA was added to the sample, mixture was hand-shaken for $2 \mathrm{~min}$ and centrifuged for $10 \mathrm{~min}$ at $5000 \mathrm{rpm}$. Supernatant was transferred onto clean-up cartridge (Oasis HLB) preconditioned with methanol and 5\% TCA. Cartridge was then rinsed with 5\% TCA, dried and eluted with $10 \mathrm{ml}$ of methanol. Obtained extract was prepared for HPLC-MS/MS analysis.
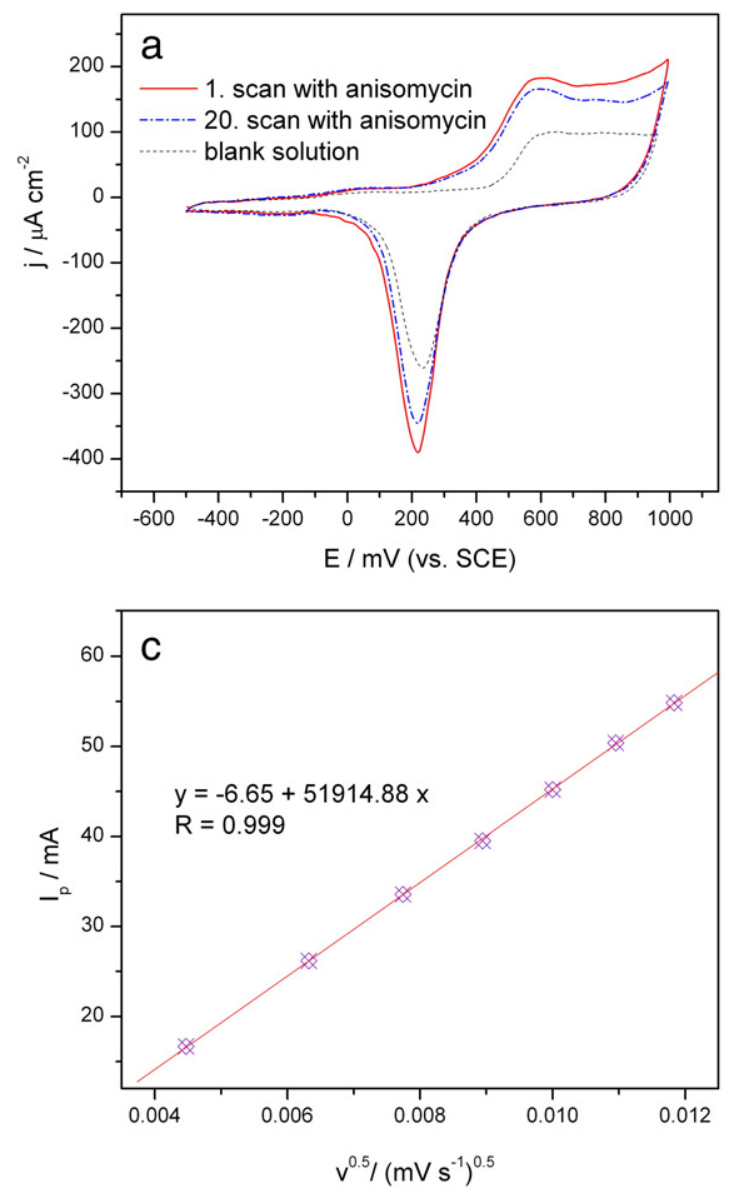

\subsection{HPLC-MS/MS analysis}

HPLC was performed using Surveyor LC system (Thermo Fisher Scientific, Waltham, MA, USA) with reverse-phase Zorbax Eclipse ${ }^{\circledR}$ XDB-C18 column, $75 \mathrm{~mm} \times 4.6 \mathrm{~mm}$ and $3.5 \mu \mathrm{m}$ (Agilent Technologies, Santa Clara, USA). The mobile phase consisted of deionized water (69\%), methanol (30\%), and 10\% acetic acid (1\%). After 5 min, column was rinsed with methanol and the initial conditions were re-established and held for $10 \mathrm{~min}$. The flow rate of the mobile phase was $0.4 \mathrm{ml} \mathrm{min}^{-1}$. Injection volume was $10 \mu \mathrm{l}$.

HPLC system was coupled to LTQ XL (Thermo Fisher Scientific) linear ion trap mass spectrometer equipped with an electrospray ionization source, operating in the positive ion mode. Fragmentation reaction of the protonated molecular ion of anisomycin ( $\mathrm{m} / \mathrm{z} 266)$ to the most intensive fragment ion $(\mathrm{m} / \mathrm{z} 206)$ was selected for quantification in the selected reaction monitoring (SRM) mode. The optimized MS/MS conditions were: source voltage $(5.0 \mathrm{kV})$, capillary temperature $\left(300{ }^{\circ} \mathrm{C}\right)$, and sheath gas ( $47 \mathrm{au}$, in $0-100$ range defined by the LTQ $\mathrm{XL}$ system).

\section{Results and discussion}

\subsection{Cyclic voltammetry}

The CVs (subsequent scans, 1-20) of anisomycin on gold electrode in $0.05 \mathrm{M} \mathrm{NaHCO}_{3}$ alongside the voltammetric response of Au electrode in blank solution (dot line) are presented in Fig. 1a. In the presence of anisomycin, the CV in the first cycle was changed so that an apparent
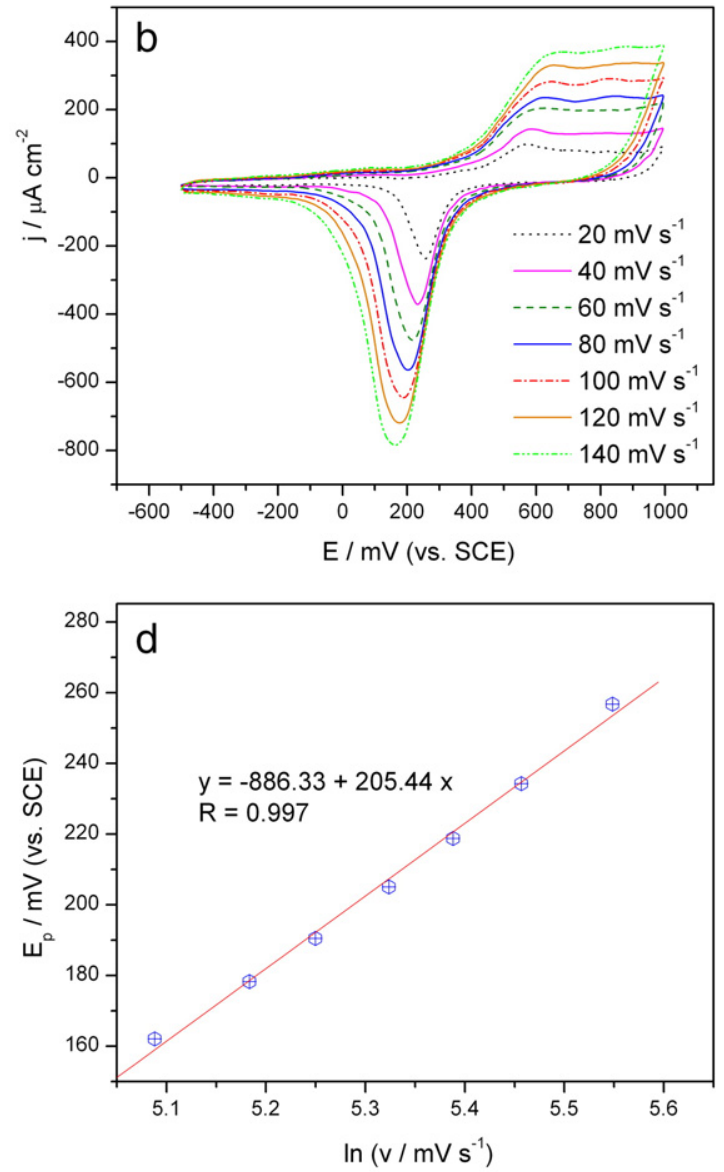

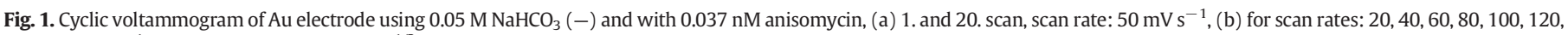
and $140 \mathrm{mV} \mathrm{s}^{-1}$, (c) plot of peak current vs. $\mathrm{v}^{1 / 2}$, (d) plot of peak potential shift vs. In of scan rates. 

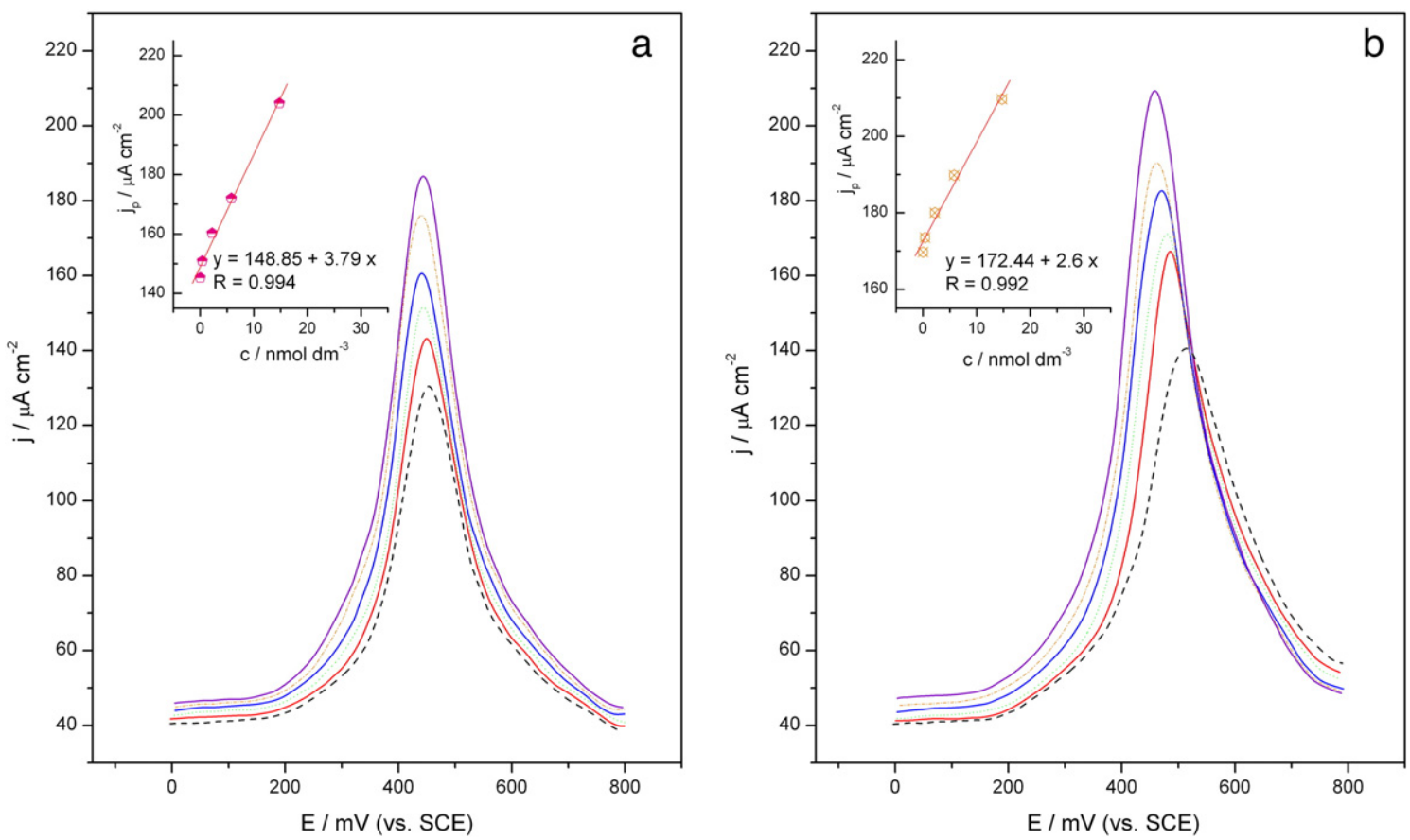

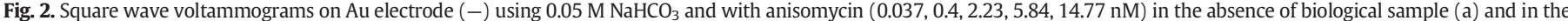

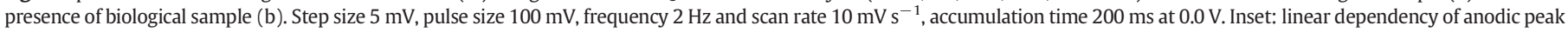
currents vs. concentration of anisomycin.

current increase occurs in the whole region of the oxide formation and reduction. The changes induced by continuous cycling are expected to be correlated with the surface oxide formation [25]. During the cycling between 1 st and 20th cycles, the voltammograms show a slight decrease of anodic currents in the area of the oxide formation.

Fig. 1b demonstrates the CVs of anisomycin containing solution at different scan rates (v). The current density increases with the increased scan rate. In Fig. 1c the relationship between peak current and $v^{1 / 2}$ is displayed showing linearity, indicating that the anisomycin oxidation is diffusion controlled process. Furthermore, the peak potential increases with increasing scan rate, and a straight line relationship is observed between peak potentials and $\ln$ of scan rates (Fig. 1d), suggesting that the anisomycin oxidation is an irreversible electrode process [26].

According to the results presented in Fig. 1b, the kinetic parameters for the anisomycin oxidation are estimated from Laviron's theory [27]. The value of $\alpha n$ is calculated from the slope of $E_{p} v s$. $\log v$. The number of electrons transferred in the electrooxidation of anisomycin was calculated to be 1.1 (approximately equal to 1 ) assuming that the first
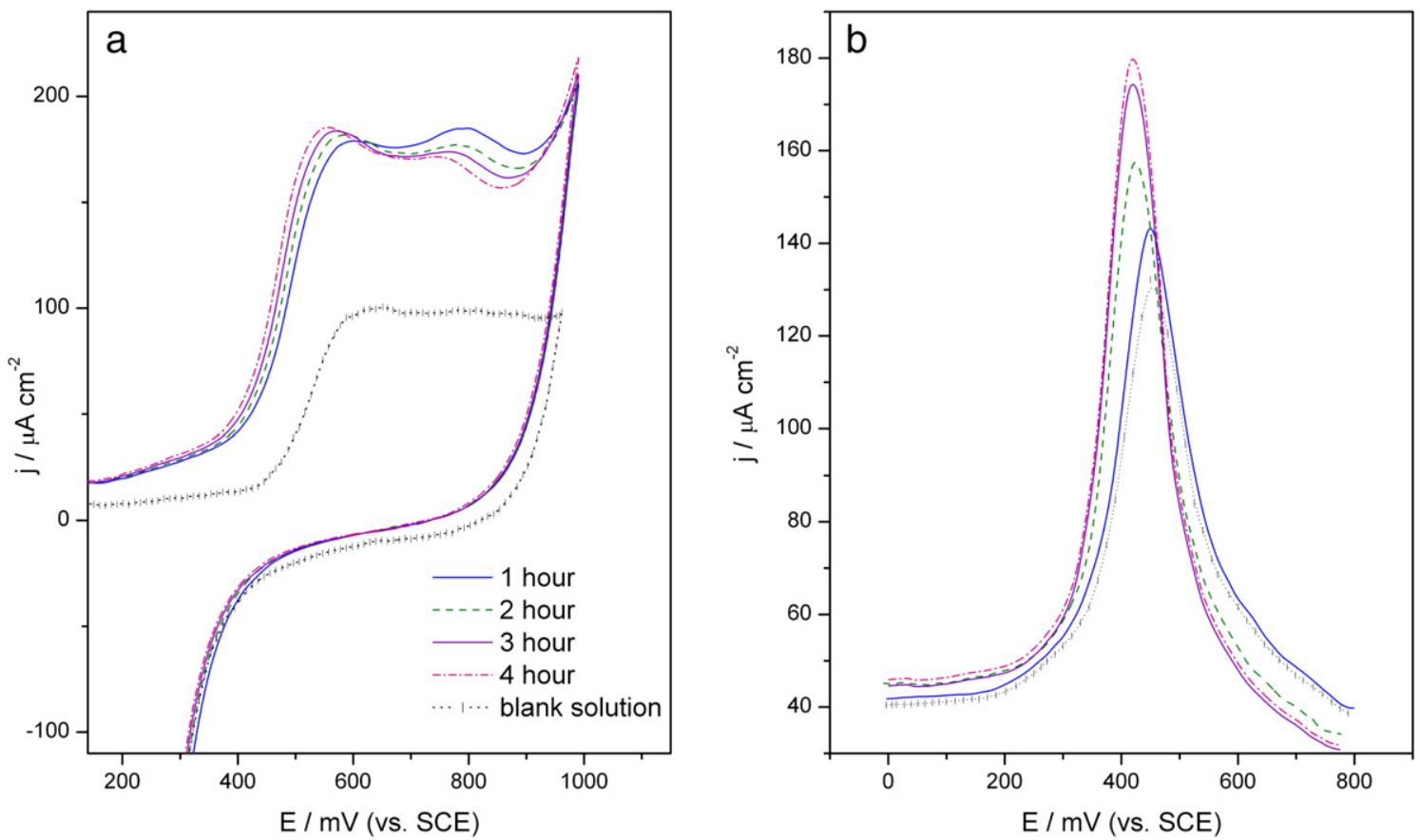

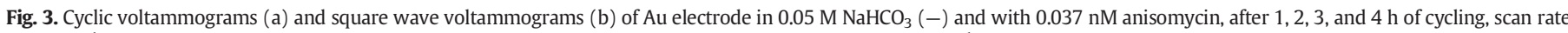
$50 \mathrm{mV} \mathrm{s}^{-1}$. Square wave parameters: step size $5 \mathrm{mV}$, pulse size $100 \mathrm{mV}$, frequency $2 \mathrm{~Hz}$ and scan rate $10 \mathrm{mV} \mathrm{s}{ }^{-1}$, accumulation time $200 \mathrm{~ms}$ at $0.0 \mathrm{~V}$. 
electron transfer is rate-determining so the transfer coefficient is equal to the symmetry factor which is 0.5 . The value of $\mathrm{k}^{\mathrm{o}}$ (heterogeneous electron-transfer rate constant) is determined from the intercept of the previous plot if the value of $\mathrm{E}^{\mathrm{O}}$ is known. The value of $\mathrm{E}^{\mathrm{o}}$ is obtained from the intercept of $E_{p} v s . v$ curve and the value is $267.2 \mathrm{mV}$. From this, $\mathrm{k}^{0}$ was calculated as $0.23 \mathrm{~s}^{-1}$.

\subsection{Square wave voltammetry}

The application of the SWV for quantitative determination of anisomycin at five different concentrations in the absence and the presence of human urine is displayed in Fig. 2. Oxidation proceeds by formation of well defined peak at approximately $450 \mathrm{mV}$. The peak currents exhibit linear dependence on the anisomycin concentrations in the range $0.037-14.76 \mathrm{nM}$ (insert in Fig. 2a). Investigated concentrations of anisomycin generate comparably higher oxidation currents and linear dependency in the presence of biological fluid in the solution (Fig. 2b). The calculated values of LOD and LOQ [28] were 1 and 4 nM, respectively, while in the presence of biological fluid the calculated values for LOD were $2 \mathrm{nM}$ and LOQ $6 \mathrm{nM}$, indicating the high sensitivity of this method.
The HPLC-MS/MS method, used for confirmation of SWV results, exhibited good linearity in the observed concentration range in the absence $(R=0.999)$ and in the presence of biological sample $(R=0.978)$.

\subsection{Long term potential cycling followed by HPLC-MS/MS analysis}

CV during $4 \mathrm{~h}$ of anisomycin oxidation (Fig. 3a) shows the appearance of the new anodic reactions with the increasing currents compared to Fig. 1a, suggesting simultaneous oxidation of anisomycin and the products of its oxidation. SWV (Fig. 3b) confirms that effect showing the increasing currents of the anodic peak.

During the cycling, samples of electrolyte were collected and analyzed by HPLC-MS/MS. It was determined that anisomycin hydrolysis occurs, and deacetylanisomycin ( $\mathrm{m} / \mathrm{z} 224)$ [29,30] was identified as the hydrolysis product chromatographically separated from anisomycin. Fig. 4 shows SRM chromatograms and MS/MS spectra of anisomycin (Fig. 4a) and its hydrolysis product (Fig. 4b) in $0.05 \mathrm{M} \mathrm{NaHCO}_{3}$. Anisomycin hydrolysis under the CV conditions (Fig. 3a) is presented in Fig. 4c. In the first two hours, the amount of anisomycin decreases while the amount of hydrolysis product increases. After that, the amounts of both anisomycin and the hydrolysis product decrease and by the end of the experiment $(4 \mathrm{~h})$ their presence was neglectable.
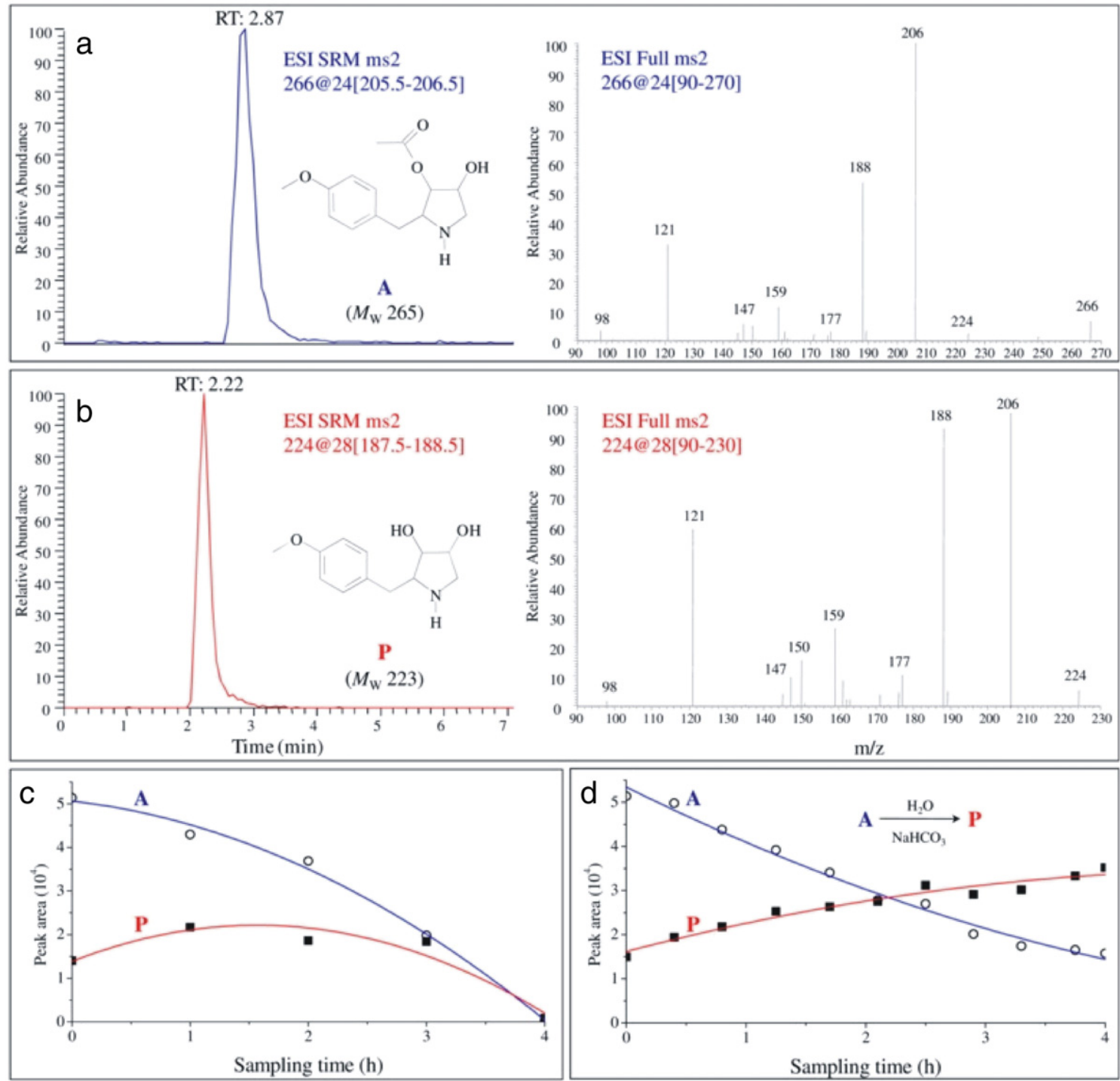

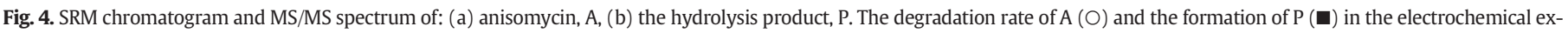
periment (c) and in $0.05 \mathrm{M} \mathrm{NaHCO}_{3}(\mathrm{~d})$. 
This confirms that after $2 \mathrm{~h}$ the electrooxidation products cause the apparent increase of anodic currents in Fig. 3. It was also determined that the hydrolysis of anisomycin proceeds in $0.05 \mathrm{M} \mathrm{NaHCO}_{3}$ without electrochemical conditions (Fig. 4d). Within the first $30 \mathrm{~min}$, only $3 \%$ of anisomycin is hydrolyzed enabling the correct electroanalytical measurements for at least $30 \mathrm{~min}$. Unlike the electrochemical experiment, the amount of hydrolysis product constantly increases and in $4 \mathrm{~h}$ only $69.5 \%$ of anisomycin is hydrolyzed.

\section{Conclusions}

Anisomycin, an immunosuppressant in low doses $(<0.1 \mu \mathrm{M})$ with possible application in treatment of autoimmune diseases and in inhibiting the transplantation rejection, was electrochemically investigated for the first time. It was determined by $\mathrm{CV}$ at gold electrode in $0.05 \mathrm{M} \mathrm{NaHCO}_{3}$ using its electrochemical activity. The CV experiments at different sweep rates show that process is irreversible and diffusion controlled. Based on SWV, the calculated values of LOD and LOQ were 1 and $4 \mathrm{nM}$ (in the absence of biological fluid), and 2 and $6 \mathrm{nM}$ (in the presence of biological fluid) indicating the high sensitivity of the proposed electroanalytical method. HPLC-MS/MS was used for quantification of anisomycin and structural identification of its hydrolysis product (deacetylanisomycin). In the first $2 \mathrm{~h}$ of long term cycling, the amount of anisomycin decreases while the amount of hydrolysis product increases and by the end of the experiment $(4 \mathrm{~h})$ their presence was neglectable.

\section{Conflict of interest}

There is no conflict of interest.

\section{Acknowledgments}

This work was supported by the Ministry of Education, Science and Technological Development of the Republic of Serbia (project No. ON172013, ON172060, and ON172007).

\section{References}

[1] B. Sobin, F. Tanner, Anisomycin, a new anti-protozoan antibiotic, J. Am. Chem. Soc. 76 (1954) 4053-4053.

[2] A. Grollman, Inhibitors of protein biosynthesis: II. Mode of action of anisomycin, J. Biol. Chem. 242 (1967) 3226-3233.

[3] T. Hori, T. Kondo, Y. Tabuchi, I. Takasaki, Q.-L. Zhao, M. Kanamori, T. Yasuda, T. Kimura, Molecular mechanism of apoptosis and gene expressions in human lymphoma U937 cells treated with anisomycin, Chem. Biol. Interact. 172 (2008) 125-140.

[4] M. Macías-Silva, G. Vazquez-Victorio, J. Hernandez-Damian, Anisomycin is a multifunctional drug: more than just a tool to inhibit protein synthesis, Curr. Chem. Biol. 4 (2010) 124-132.

[5] Z. Tang, F. Xing, D. Chen, Y. Yu, C. Yu, J. Di, J. Liu, In vivo toxicological evaluation of anisomycin, Toxicol. Lett. 208 (2012) 1-11.

[6] K. Nader, G. Schafe, J. Le Doux, Fear memories require protein synthesis in the amygdala for reconsolidation after retrieval, Nature 406 (2000) 722-726.

[7] J. Debiec, J.E. LeDoux, K. Nader, Cellular and systems reconsolidation in the hippocampus, Neuron 36 (2002) 527-538.

[8] A. Suzuki, S. Josselyn, P. Frankland, S. Masushige, A. Silva, S. Kida, Memory reconsolidation and extinction have distinct temporal and biochemical signatures, J. Neurosci. 24 (2004) 4787-4795.
[9] H. Cohen, Z. Kaplan, M. Matar, U. Loewenthal, N. Kozlovsky, J. Zohar, Anisomycin, a protein synthesis inhibitor, disrupts traumatic memory consolidation and attenuates posttraumatic stress response in rats, Biol. Psychiatry 60 (2006) 767-776.

[10] C. Rodriguez-Ortiz, P. Garcia-DeLaTorre, E. Benavidez, M. Angeles Ballesteros, F. Bermudez-Rattoni, Intrahippocampal anisomycin infusions disrupt previously consolidated spatial memory only when memory is updated, Neurobiol. Learn. Mem. 89 (2008) 352-359.

[11] R.N. Sadowski, C.E. Canal, P.E. Gold, Lidocaine attenuates anisomycin-induced amnesia and release of norepinephrine in the amygdala, Neurobiol. Learn. Mem. 96 (2011) 136-142.

[12] A.V. Sharma, F.E. Nargang, C.T. Dickson, Neurosilence: profound suppression of neural activity following intracerebral administration of the protein synthesis inhibitor anisomycin, J. Neurosci. 32 (2012) 2377-2387.

[13] R. Pena, A. Pereira-Caixeta, M. Moraes, G. Pereira, Anisomycin administered in the olfactory bulb and dorsal hippocampus impaired social recognition memory consolidation in different time-points, Brain Res. Bull. 109 (2014) 151-157.

[14] A. Greenberg, R. Ward-Flanagan, C. Dickson, D. Treit, ANI inactivation: unconditioned anxiolytic effects of anisomycin in the ventral hippocampus, Hippocampus 24 (2014) 1308-1316.

[15] J. Curtin, T. Cotter, Anisomycin activates JNK and sensitises DU 145 prostate carcinoma cells to Fas mediated apoptosis, Br. J. Cancer 87 (2002) 1188-1194.

[16] H. Yang, H.J. Choi, S.H. Park, J.S. Kim, Y. Moon, Macrophage inhibitory cytokine-1 (MIC-1) and subsequent urokinase-type plasminogen activator mediate cell death responses by ribotoxic anisomycin in HCT-116 colon cancer cells, Biochem. Pharmacol. 78 (2009) 1205-1213.

[17] D. Monaghan, E. O'Connell, F.L. Cruickshank, B. O'Sullivan, F.J. Giles, A.N. Hulme, H.O Fearnhead, Inhibition of protein synthesis and JNK activation are not required for cell death induced by anisomycin and anisomycin analogues, Biochem. Biophys. Res. Commun. 443 (2014) 761-767.

[18] L.H. Zhang, J.L. Zhang, Y.C. Liu, Z.Y. Cao, J.M. Han, J. Yang, J. Dong, Isolation and structural speculation of herbicide-active compounds from the metabolites of Pythium aphanidermatum, J. Integr. Agric. 12 (2013) 1026-1032.

[19] J.S. Reddy, A.R. Kumar, B.V. Rao, A new approach to (+)-anisomycin, Tetrahedron Asymmetry 16 (2005) 3154-3159.

[20] R. Kirchmeier, R. Upton, Simultaneous determination of vancomycin, anisomycin, and trimethoprim lactate by High Pressure Liquid Chromatography, Anal. Chem. 50 (1978) 349-351.

[21] E.P. Rusanova, T.A. Alekhova, G.B. Fedorova, G.S. Katrukha, An antibiotic complex produced by Streptomyces werraensis 1365 T, Appl. Biochem. Microbiol. 36 (2000) 486-490.

[22] T. Abdel-Aal, N. Abdelwahed, G. Awad, E. Diwany, A.I.B. Haroun, Improvement of anisomycin production through mutation and medium optimization for Streptomyces griseolus, Aust. J. Basic Appl. Sci. 5 (2011) 2637-2648.

[23] N.P. Trišovic, B.Dj. Božic, J.D. Lovic, V.D. Vitnik, Ž.J. Vitnik, S.D. Petrovic, M.L. Avramov Ivic, Electrochemical characterization of phenytoin and its derivatives on bare gold electrode, Electrochim. Acta 161 (2015) 378-387.

[24] R. Cazorla-Reyes, R. Romero-González, A. Garrido Frenich, M.A. Rodríguez Maresca, J.L. Martínez Vidal, Simultaneous analysis of antibiotics in biological samples by ultra high performance liquid chromatography-tandem mass spectrometry, J. Pharm. Biomed. Anal. 89 (2014) 203-212.

[25] J. Mirković, J. Lović, M. Avramov Ivić, D. Mijin, Electrooxidative behavior of arylazo pyridine dyes and their inclusion complexes on gold electrode in $0.1 \mathrm{M} \mathrm{NaOH}$, Electrochim. Acta 137 (2014) 705-713.

[26] A.J. Bard, L.R. Faulkner, Electrochemical Methods: Fundamentals and Applications, 2nd ed. John Wiley and Sons, Inc., New York, 2001.

[27] E. Laviron, The use of linear potential sweep voltammetry and of a.c. voltammetry for the study of the surface electrochemical reaction of strongly adsorbed systems and of redox modified electrodes, J. Electroanal. Chem. 100 (1979) 263-270.

[28] O.B. da Silva, S.A.S. Machado, Evaluation of the detection and quantification limits in electroanalysis using two popular methods: application in the case study of paraquat determination, Anal. Methods 4 (2012) 2348-2354

[29] P. Hutin, M. Haddad, M. Larchevêque, Stereoselective synthesis of (-)deacetylanisomycin, Tetrahedron Asymmetry 11 (2000) 2547-2553.

[30] K.S. Reddy, B.V. Rao, A facile and stereoselective synthesis of the C-2 epimer of (+)deacetylanisomycin, Tetrahedron Asymmetry 22 (2011) 190-194. 